\title{
Об использовании арсенида индия в качестве материала волновода при измерениях методом нарушенного полного внутреннего отражения
}

\author{
(C) С.А. Карандашев ${ }^{1}$, Т.С. Лухмырина ${ }^{1}$, Б.А. Матвеев ${ }^{1,2}$, М.А. Ременный ${ }^{1}$, А.А. Усикова ${ }^{1}$ \\ ${ }^{1}$ ФТИ им. А.Ф. Иоффре РАН, \\ 194021 Санкт-Петербург, Россия \\ ${ }^{2}$ ООО „ИофрфеЛЕД“, \\ 194064 Санкт-Петербург, Россия \\ ฯ e-mail: ioffeled@mail.ru \\ Поступила в редакцию 03.03.2021 г. \\ В окончательной редакции 03.03.2021 г. \\ Принята к публикации 01.06.2021 г.
}

Рассмотрены вольт-амперные характеристики и фототок „монолитных“ диодных оптопар, оптически связанных общей для них подложкой из InAs, оценена возможность использования значений фототока для измерения ослабления „исчезающей волны“ при полном внутреннем отражении от границы раздела волновод (подложка из InAs)/поглощающее анализируемое вещество.

Ключевые слова: оптические сенсоры, датчики химического состава вещества, диодные оптопары, анализаторы МНПВО, анализаторы исчезающей волны, фотодиоды среднего ИК диапазона, светодиоды среднего ИК диапазона.

DOI: $10.21883 /$ OS.2021.09.51350.1961-21

\section{Введение}

Определение концентрации и/или качественного состава вещества с помощью спектроскопии является одной из наиболее часто решаемых задач инфракрасной оптоэлектроники с использованием полупроводниковых лазеров [1,2], светодиодов (СД) [3-5] и фотодиодов (ФД) [1-5]. Для реализации измерений характеристик твердых или жидких сред, имеющих высокий коэффициент поглощения, чаще всего используют эффект частичного выхода зондирующего излучения за пределы оптически плотного вещества при его полном внутреннем отражении, т.е. так называемый эффект „исчезающей волны“ (evanescent wave). Для увеличения чувствительности/степени ослабления зондирующего излучения (исчезающей волны) используют волновод, обеспечивающий многократное отражение лучей от границы раздела волновод/анализируемое вещество. В литературе такие волноводы, чаще всего в виде трапецоида, нередко именуют элементами (кристаллами) многократно нарушенного полного внутреннего отражения (MHПВО) (ATR crystal) [6]. В качестве материала такого волновода, т.е. прозрачной среды с высоким показателем преломления $\tilde{n}$, могут быть использованы многие вещества, например, халькогенидные стекла $(\tilde{n}=2.3-3)[7,8]$, сапфир $(\tilde{n}=1.8)$ и полупроводники $(\tilde{n}=3.4-4)$. Среди последних наиболее популярными у крупных производителей, а значит и у потребителей, являются $\mathrm{Ge}, \mathrm{ZnSe}$ и $\mathrm{Si}$, при этом габариты и некоторые другие характеристики промышленно изготавливаемых полупроводниковых элементов МНПВО не всегда от- вечают в полной мере тенденции миниатюризации в приборостроении.

В данной работе нами рассматриваются особенности и связанные с ними преимущества при использовании в качестве кристалла МНПВО арсенида индия $(\tilde{n}=3.4)$.

\section{Предварительные замечания}

Одним из ключевых свойств арсенида индия, важных при создании кристаллов МНПВО, помимо высокого коэффициента преломления $\tilde{n}$ является наличие плоскостей наименьшей спайности $\{110\}$, характерных для всех полупроводников $A^{3} B^{5}$ и позволяющих получать требуемую форму кристалла, например, трапецоида, простым скалыванием пластины, вырезанной в направлении [111], по этим плоскостям. Процедура скалывания по плоскостям $\{110\}$ для создания требуемой формы образца давно освоена в технологии создания инжекционных лазеров, в которых пары параллельных друг другу плоскостей образуют резонатор Фабри-Перо. Однако использование процедуры скалывания в технике методов МНПВО было крайне ограниченным.

При использовании в качестве зондирующего источника СД форма кристалла МНПВО в виде трапецоида не является строго необходимой. В отличие от лазеров диаграмма направленности у миниатюрных СД, т.е. у СД не обремененных фокусирующими элементами (линзами, рефлекторами), широкая, описываемая распределением Ламберта. Это означает, что значительная часть введенного в InAs излучения СД будет иметь углы падения, превышающие угол полного внутреннего 
отражения на границе раздела InAs/воздух $\left(\alpha_{\text {crit }}=17^{\circ}\right)$ или InAs/анализируемое вещество, т. е. будет создавать полезный сигнал при измерениях методом МНПВО. При этом в отличие от датчика с узконаправленным лучом в датчике на основе СД возникает набор лучей/углов отражений с разным итоговым количеством отражений от границы раздела.

Из этого следует, что кристалл МНПВО может иметь в том числе и форму параллелепипеда, причем источник излучения (СД) и приемник (ФД) могут быть интегрированы с таким волноводом без каких-либо дополнительных фокусирующих элементов, например, с использованием эпитаксиальной технологии выращивания монолитных полупроводниковых структур с последующим использованием многостадийной фотолитографии и выкалывания [9]. Отметим, что отечественная промышленность по-прежнему предлагает широкую номенклатуру подложек InAs, прозрачных в средней ИК области спектра [10]. Схема, поясняющая ход лучей, в том числе и испытавших многократное отражение в одном из таких „монолитных“ датчиков, полученных на подложке полупроводника $A^{3} B^{5}$, ориентированной в плоскости (111), представлена на рис. 1.

\section{Образцы и методы исследования}

Три типа образцов в виде диодных линеек $1 \times 4$ с рабочей длиной волны излучения $\lambda_{1 \max }=3.6 \mu \mathrm{m}$ (\#S6269) и $\lambda_{2 \max }=3.7 \mu \mathrm{m}(\# \mathrm{~S} 6267, \# \mathrm{~S} 6279)\left(\mathrm{FWHM}_{1,2} \approx 0.5 \mu \mathrm{m}\right)$ получали из гетероструктур (ГC) $p$-InAsSbP/n-InGaAsSb, выращенных на подложке $n^{+}$-InAs (111). Четыре квадратные мезы с индивидуальными анодами располагались в линию вдоль длинной стороны; общий для всех четырех элементов П-образный катод располагался сбоку от мез. В области $p-n$-перехода мезы имели размеры $70 \times 70 \mu \mathrm{m}(\# \mathrm{~S} 6269, \#$ S6279) либо $130 \times 130 \mu \mathrm{m}$ (\#S6267), при этом квадратные аноды занимали бо́льшую часть площади плоской поверхности мез. Боковые поверхности чипа размером $\sim 1 \times 2 \mathrm{~mm}$ получали раскалыванием эпитаксиальной пластины толщиной $\sim 150 \mu \mathrm{m}$ вдоль созданных с помощью фотолитографии канавок разделения, образующих ортогональную сетку; при этом длинные стороны чипа (на рис. 1 они лежат в плоскости чертежа) были образованы сколотыми плоскостями $\{110\}$ и частично участками канавок разделения (не показаны на рис. 1), а короткие, перпендикулярные им боковые стороны содержали набор разных кристаллографических плоскостей и криволинейных микроповерхностей $n^{+}$-InAs. На тыльной (плоской) стороне $n^{+}$-InAs некоторые образцы (\#S6279) содержали периодический рельеф (фотонный кристалл, ФК) в виде гексагонально упакованных глухих отверстий с периодом $3 \mu \mathrm{m}$ (см. фото в нижнем правом углу на рис. $1, a)$.

Изучались как отдельные (несмонтированные) чипы, так и чипы, смонтированные на монтажных платах из $\mathrm{Si}$ по методу флип-чип. В первом случае для подключения к диодам использовали прижимные контакты к образцу, установленному на медном основании (рис. $1, a)$, во втором - производили стыковку чипа к монтажной плате методом припайки и далее присоединение к корпусу ТО-5 (рис. $1, b)$.

Более подробное описание подобных образцов, их электролюминесцентных свойств и ИК изображений можно найти в $[9,11]$.

\section{Результаты измерений и их обсуждение}

На рис. 2, $a$ и $b$ приведены темновая $\left(I_{\mathrm{LED}}=0\right)$ и „световые“ $\left(I_{\text {LED }}=10-50 \mathrm{~mA}\right)$ вольт-амперные характеристики (BAX), измеренные в непрерывном режиме для одного из элементов несмонтированной диодной линейки $1 \times 4$, выбранного в качестве ФД. Небольшое смещение темновой BAX в область отрицательных напряжений связано с особенностью измерительной установки. Из рис. 2, $b$ отчетливо видно смещение ВАХ ФД в область отрицательных значений токов, связанное с появлением фототока при поглощении излучения активированного СД. С увеличением тока СД (0-50 mA) динамическое сопротивление в нуле смещения $R_{0}$ в ФД уменьшалось с $3.9 \mathrm{k} \Omega\left(0.19 \Omega \cdot \mathrm{cm}^{2}\right)$ до $3.6 \mathrm{k} \Omega$ $\left(0.17 \Omega \cdot \mathrm{cm}^{2}\right)$, отражая, очевидно, некоторый разогрев всего чипа при выделении джоулева тепла (см. обсуждение вопросов джоулева разогрева в гетероструктурах, в которых $p-n$-переход удален от теплоотвода из-за относительно толстой подложки InAs [12] или приближен к нему в образцах типа флип-чип $[12,13])$.

Полученная из данных на рис. 2 зависимость фототока ФД $I_{\mathrm{ph}}$ при нулевом смещении $(U=0)$ и при $U=-0.1 \mathrm{~V}$ от тока СД представлена на рис. 3 (см. точки в виде кружочков и заполненных квадратиков). В обоих случаях под фототоком понималась разность тока при активации СД и темнового тока: $I_{\mathrm{ph}}=\left|I_{\text {light }}-I_{\text {dark }}\right|$. Там же на рис. 3 приведены значения $I_{\mathrm{ph}}$ в дальнем от СД элементе линейки (на рис. 1 этот ФД обозначен под № 4), смонтированной на контактной плате по методу флип-чип, при разных значениях тока через СД (на рис. 1 он обозначен под № 1). Как видно из рис. 3, величина фототока $I_{\mathrm{ph}}$ в несмонтированном чипе лишь немногим уступает $I_{\mathrm{ph}}$ в линейке на монтажной плате. При этом в области малых токов зависимость $I_{\mathrm{ph}}$ от $I_{\mathrm{LED}}$ близка к линейной; в области больших токов имеет место отклонение от линейной зависимости, вероятнее всего, связанное с возрастанием безызлучательной оже-рекомбинации при увеличении концентрации инжектированных носителей заряда. Там же на рис. 3 для сравнения приведены значения импульсных $(10 \mu \mathrm{s}, 500 \mathrm{~Hz})$ фототоков „немонолитного“ датчика метана на основе дискретных ФД и СД, содержащих иммерсионные линзы диаметром $3.5 \mathrm{~mm}$ и полупроводниковые структуры $p$-InAsSbP/n-InAs $(\tilde{n}=3.4 \mu \mathrm{m})$, описанные в [14]. Оптическая связь двух пространственно разнесенных индивидуальных диодов осуществлялась в [14] с помощью сферического зеркала диаметром $13.6 \mathrm{~cm}$, и предполагалось, 


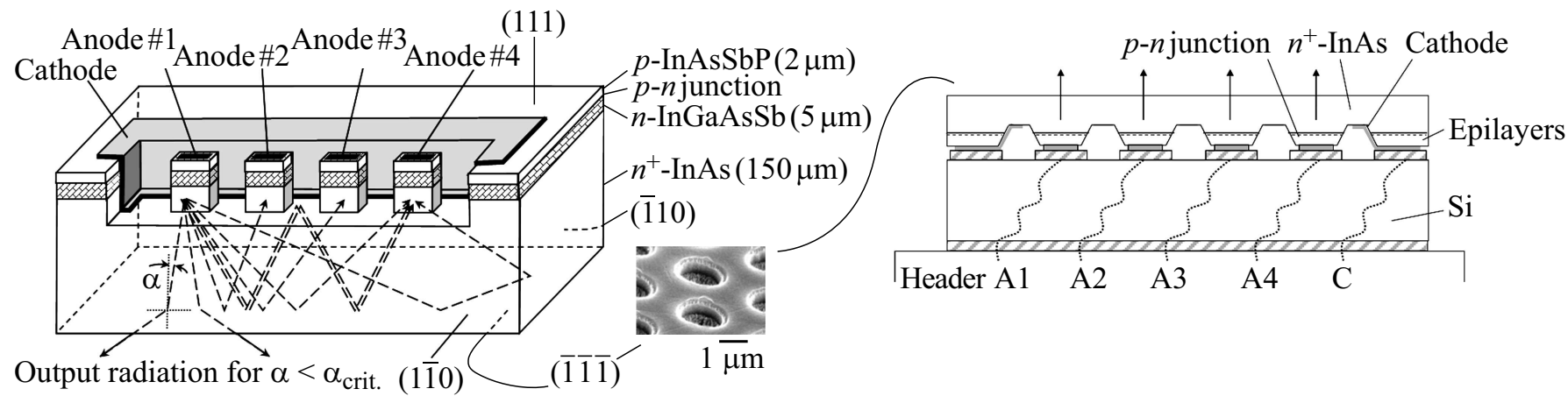

Рис. 1. Упрощенная схема чипа линейки $1 \times 4$ для монтажа по методу флип-чип с двумя сколотыми боковыми плоскостями $\{110\}$ и двумя гладкими поверхностями $\{111\}(a)$ и схема сечения того же чипа, но смонтированного на кремниевой контактной плате $(\mathrm{Si})(b)[11]$. В круглых скобках - обозначение кристаллографических плоскостей; стрелками показаны лучи, покидающие кристалл при $\alpha<\alpha_{\text {crit }}$, а также некоторые из лучей, создающих фототок в мезах (фотодиодах) под № 2, № 3 и № 4 при приложении прямого смещения к мезе (диоду) № 1 . В нижнем правом углу рис. $a$ ) приведена фотография поверхности подложки $n^{+}-$InAs c периодическим рельефом в виде гексагонально упакованных глухих отверстий (поле $\sim 3.5 \times 5 \mu \mathrm{m}^{2}$ ).
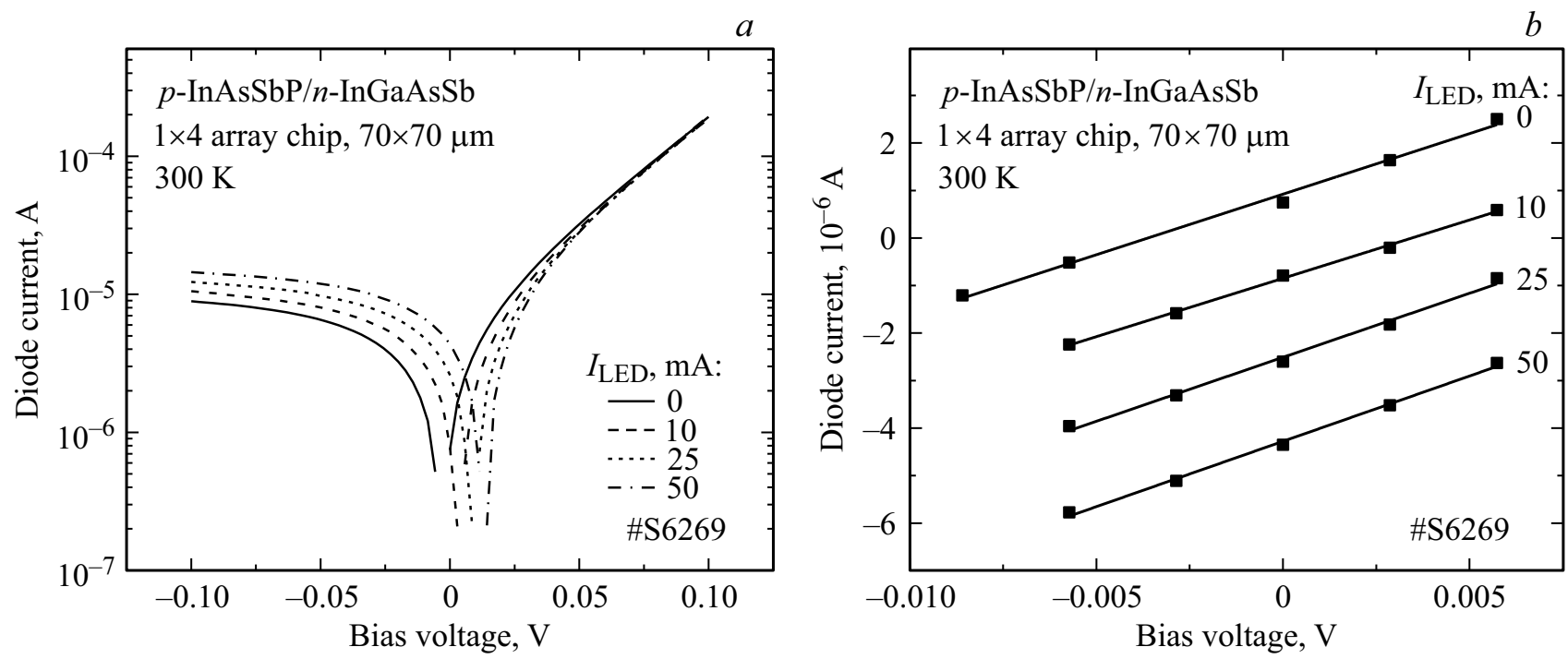

Рис. 2. Темновая $\left(I_{\mathrm{LED}}=0\right)$ и „световые“ $\left(I_{\mathrm{LED}}=10-50 \mathrm{~mA}\right)$ вольт-амперные характеристики одного из элементов чипа несмонтированной диодной линейки $1 \times 4\left(\lambda_{1 \max }=3.6 \mu \mathrm{m}\right)$, выбранного в качестве $Ф Д$.

что „аналит“ (метано-воздушная смесь) находился между диодами и зеркалом. Как видно из рис. 3, значения фототока для пары СД/ФД $(\lambda=3.4 \mu \mathrm{m})$ в [14] в $2-3$ раза превышает $I_{\mathrm{ph}}$ для пар СД/ФД $(\lambda=3.6-3.7 \mu \mathrm{m})$, что мы связываем прежде всего с уменьшением квантового выхода электролюминесценции с увеличением длины волны, сопоставимым с общей тенденцией снижения мощности средневолновых ИК СД $[3,15]$. Не является исключением из общего правила также и сублинейная зависимость фототока от тока накачки для пары СД/ФД $(\lambda=3.4 \mu \mathrm{m})$, связанная, как уже упоминалось ранее, с возрастанием скорости безызлучательных процессов.

Смонтированные на платах линейки представляют собой один из вариантов датчика МНПВО, поскольку приведение аналита в контакт с подложкой $n^{+}-\operatorname{InAs}$ должно приводить к перераспределению излучения внутри полупроводникового чипа и последующему уменьшению фототока (фотосигнала). На рис. 4 приведены изменения фотоэдс, создаваемые в дальних от СД элементах датчиков при нанесении на их поверхности дистиллированной воды $(\tilde{n}=1.33$, крайние левые точки), спирта $(\tilde{n}=1.36$, средние точки) и толуола $(\tilde{n}=1.5$, крайние правые точки) от показателя преломления $\tilde{n}$ при фиксированном токе через светодиодный элемент $(I=10 \mathrm{~mA})$. Как видно из рис. 4, несмотря на немонотонный характер зависимости, не имеющей пока у авторов однозначной интерпретации, имеет место хорошая воспроизводимость/корреляция результатов, полученных на 


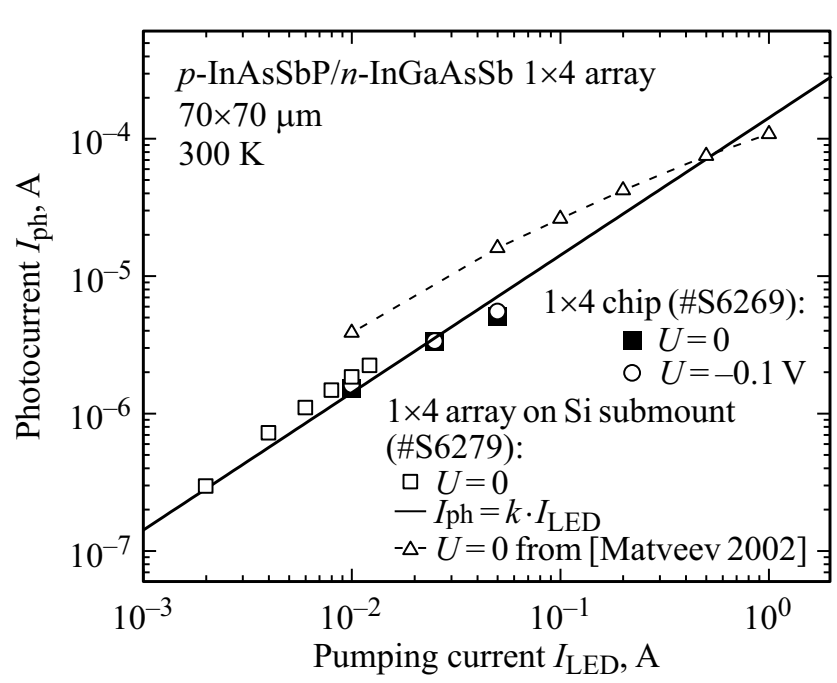

Pис. 3. Зависимость фототока ФД от тока накачки СД в чипе $(\boldsymbol{\square}$, о) и в смонтированной линейке $(\square)$ от тока через светодиод. $\triangle$ - данные из работы [14] для пары иммерсионный СД иммерсионный ФД $(\lambda=3.4 \mu \mathrm{m})$.

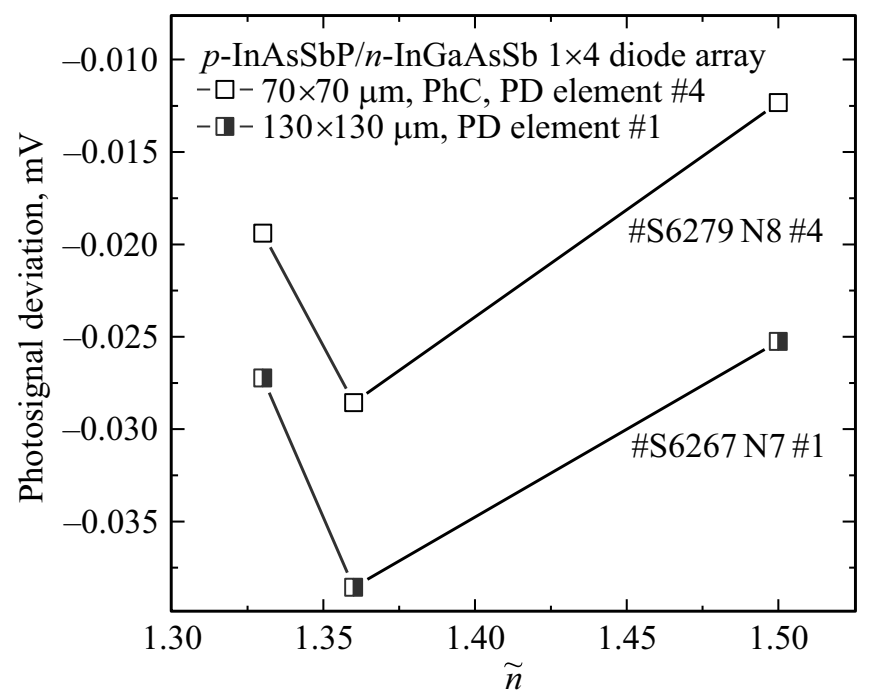

Рис. 4. Изменение фотосигнала в двух линейках $1 \times 4 \lambda_{2 \max }=3.7 \mu \mathrm{m} \quad$ с фотонным кристаллом ( $\left.\square\right)$ и без него (ם) при контакте тыльной стороны подложки (111) с водой $(\tilde{n}=1.33)$, спиртом $(\tilde{n}=1.36)$ и толуолом $(\tilde{n}=1.5)$.

\section{El-Peacetalero}

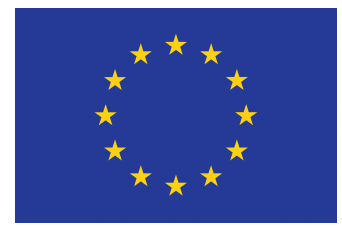

Рис. 5. Логотип проекта „Встроенные Электронные Решения для Инновационных Сканирующих Устройств Диагностики Полимеров на Основе Источников Излучения“ \#945320.

двух датчиках с несколько различающимися характеристиками.

\section{Заключение}

Таким образом в работе показано, что оптическая связь между СД и ФД через прозрачную подложку в монолитной гетероструктуре, выращенной на подложке InAs, позволяет получать значения фототоков (полезных сигналов), сопоставимых с полезными сигналами, достигаемыми в традиционных „немонолитных“ конфигурациях датчиков химического состава, например, с использованием СД и ФД с улучшенными за счет иммерсии характеристиками. При этом в монолитном датчике отпадает необходимость использовать дополнительные оптические элементы, включая внешний кристалл МНПВО, линзы и отражатели; подложка InAs выполняет функцию кристалла МНПВО, при этом она составляет единое целое с СД и с ФД. Это открывает возможность использования методов фотолитографии при создании миниатюрных и недорогих чувствительных датчиков, например, датчиков, измеряющих характеристики твердых или жидких сред. Уменьшение линейных размеров датчика не сопровождается сколько-нибудь существенным снижением его чувствительности, поскольку при пропорциональном уменьшении размеров кристалла МНПВО фиксированной геометрической формы количество отражений от границы раздела с анализируемым веществом сохраняется.

Ослабление излучения вызвано, главным образом, поглощением исчезающей волны и изменением распределения излучения внутри подложки при отражении от границы раздела подложка InAs/аналит. Приведенные в работе прототипы конструкций не являются оптимальными для получения максимально возможной чувствительности в методе МНПВО, но, несмотря на это, приведенные данные (рис. 4) показывают возможность их использования как для идентификации жидкостей (в данном случае - воды, спирта и толуола), так и для количественного анализа химического состава (концентрации) смесей веществ с помощью монолитных полупроводниковых структур на основе InAs. Предложенный подход вскоре будет нами распространен и на другие датчики, материалы/структуры, например, имеющие две рабочие длины волны зондирующего излучения [16] и/или использующие подложки $\mathrm{GaAs}, \mathrm{Si}$ и т.д.

\section{Благодарности}

Авторы выражают благодарность Н.Д. Ильинской и H.M. Стусю за помощь и поддержку.

\section{Финансирование работы}

Выполнение этой работы связано с обязательствами ФТИ им. А.Ф. Иоффе, определенными соглашением касательно проекта El-Peacetolero, получившего финансирование для участников рамочной программы Европейского Союза по развитию научных исследований и технологий „Horizon 2020“ по грантовому соглашению \#945320 (рис. 5). 


\section{Конфликт интересов}

Авторы заявляют, что у них нет конфликта интересов.

\section{Список литературы}

[1] Lambrecht A., Schmitt K. // Mid-infrared Optoelectronics. 1st Edition. Materials, Devices, and Application / Ed. by Tournié E., Cerutti L. Woodhead Publishing Series in Electronic and Optical Materials. 2019. P. 661. https://doi.org/10.1016/B978-0-08-102709-7.00016-4.

[2] Spagnolo V., Patimisco P., Tittel F.K. // Mid-infrared Optoelectronics. 1st Edition. Materials, Devices, and Application / Ed. by Tournié E., Cerutti L., Woodhead Publishing Series in Electronic and Optical Materials. 2019. P. 597.

[3] Krier A., Repiso E., Al-Saymari F., Carrington P.J., Marshall A.R.J., Qi L., Krier S.E., Lulla K.J., Steer M., MacGregor C., Broderick C.A., Arkani R., O'Reilly E., Sorel M., Molina S.I., De La Mata M. // Mid-infrared Optoelectronics. 1st Edition. Materials, Devices, and Application / Ed. by Tournié E., Cerutti L. Woodhead Publishing Series in Electronic and Optical Materials. 2019. P. 59.

[4] Матвеев Б.А., Сотникова Г.Ю. // Опт. и спектр. 2019. T. 127. № 2. C. 300; Matveev B.A., Sotnikova G.Yu. // Opt. and Spectrosc. 2019. V. 127. N 2. P. 322. doi 10.1134/S0030400X19080198

[5] Ribes C.A., BenChouikha M. Патент Франции № FR3059104. 2020.

[6] Комов А.П., Власова И.В., Терехова Е.Н. // Вестник Омского университета. 2018. Т. 23. № 1. С. 26. doi 10.25513/1812-3996.2018.23(1).26-34

[7] Romanova E.A., Korsakova S., Komanec M., Nemecek T., Velmuzhov A., Sukhanov M., Shiryaev V.S. // IEEE J. Selected Topics in Quantum Electronics. 2017. V. 23. N 2. P. 5601507.

[8] Matveev B.A., Zotova N.V., Karandashev S.A., Remennyi M.A., Stus' N.M., Talalakin G.N. // Proc. 1-st International Conf. on Advanced Optoelectronics and Lasers (CAOL'2003). 2003. Alushta, Crimea, Ukraine. 2003. V. 2. P. 138.

[9] Матвеев Б.А. Патент РФ № 2727560, 2020 (см. также заявку на изобретение PCT/RU2021/000025).

[10] Комков О.С., Фирсов Д.Д., Ковалишина Е.А., Петров А.C. // Прикладная физика. 2014. № 4. С. 9.

[11] Matveev B.A., Zadiranov Yu.M., Zakgeim A.L., Ilinskaya N.D., Karandashev S.A., Remennyy M.A., Stus' N.M., Usikova A.A., Cherniakov A.E. // Proc. SPIE. 2010. V. 7609. P. 76090I-1. doi 10.1117/12.841689

[12] Зотова Н.В., Ильинская Н.Д., Карандашев С.А., Матвеев Б.А., Ременный М.А., Стусь Н.М. // ФТП. 2008. Т. 42. № 6. C. 641; Zotova N.V., Ilinskaya N.D., Karandashev S.A., Remennyy M.A., Stus' N.M. // Semiconductors. 2008. V. 42. N 6. P. 625.

[13] Lawler J.V., Currano J. // Proc. SPIE. 2008. V. 6942. P. 69420E-1. doi 10.1117/12.778719

[14] Matveev B.A., Zotova N.V., Karandashev S.A., Remennyy M.A., Stus' N.M., Talalakin G.N. // Proc. SPIE. 2002. V. 4650. P. 173.

[15] Электронный ресурс. Режим доступа: http://www.ioffeled.com

[16] Климов А.А., Кунков Р.Э., Лебедева Н.М., Лухмырина Т.С., Матвеев Б.А., Ременный М.А. // Тезисы докл. международной конф. ФизикА. С.-Петербург, 2020. С. 289, http://physica.spb.ru/ (in Russian) 